\title{
POLÍTICAS PÚBLICAS PARA COMUNIDADES QUILOMBOLAS: uma luta em construção
}

\author{
PUBLIC POLICIES FOR MAROONS COMMUNITIES: \\ a building in fight
}

\author{
André Ricardo Fonsêca da Silva*
}

\begin{abstract}
Resumo
O presente artigo trata da construção de políticas públicas para comunidades quilombolas, dialogando com a história dos africanos, a partir da travessia do Atlântico, com o interesse do capital no modo de produção escravocrata, que fora muito usado no Brasil na época da colonização portuguesa. Além disso, analisa as políticas públicas específicas construídas no contexto brasileiro para os quilombolas, dando ênfase ao Programa Brasil Quilombola. Para o desenvolvimento da pesquisa fizemos uso da abordagem qualitativa; concomitantemente, foi feito uso da historiografia para entendermos a ressemantização da palavra quilombola. Além disso, utilizamos o método histórico para reconstruirmos a história do artigo 68 do ADCT da Constituição Federal de 1988. Fizemos também consultas a dados primários e secundários de órgãos públicos. Concluiu-se que a regularização fundiária definitiva junto com a concretização de políticas públicas específicas são o caminho para construção da cidadania quilombola, pois permitirá que haja uma segurança jurídica para os quilombolas.
\end{abstract}

Palavras-chave: Políticas Públicas. Quilombolas. Cidadania. Escravidão.

\begin{abstract}
This article deals with the construction of public policies for maroons communities, talking history of Africans from across the Atlantic, with the interests of capital in the slave mode of production, which had been widely used in Brazil at the time of Portuguese colonization. It analyzes the specific public policies built in the Brazilian context for the Maroons, with emphasis on Brazil Maroon Program. For the development of research made use of a qualitative approach, simultaneously it was made use of history to understand the resemantization the maroon word. In addition, we use the history method to reconstruct the history of Article 68 ADCT of the Federal Constitution of 1988. We also made visits to primary and secondary data from government agencies. It was concluded that the definitive regularization along with the implementation of specific public policies are the way to build the maroon citizenship, as it will allow that there is a legal certainty for the Maroons.
\end{abstract}

Keywords: Public Policy. Maroons. Citizenship. Slavery.

\section{Introdução}

O comércio europeu de negros iniciou-se antes da descoberta do Brasil, como uma espécie de subproduto da exploração marítima da costa ocidental africana. E, aproximadamente nessa época, começou a colonização das ilhas atlânticas descobertas por Portugal, vindo a

\footnotetext{
* Professor Adjunto da graduação e pós-graduação da UNIPÊ e da ESA-PB. Doutor em Políticas Públicas e Formação Humana
} (UERJ).E-mail: professor.andrefonseca@gmail.com. 
ser utilizado no Brasil o modelo parecido com o aplicado nas Ilhas da Madeira e dos Açores, conjugando monocultura açucareira e mão de obra escrava.

Nesse sentido, o sistema escravista entrou na sociedade brasileira no período colonial. Porém, apesar de detalhes históricos contados por autores coloniais, como Gaspar Barleu (1974) e Rocha Pita, há uma escassez documental em relação a um movimento que marcou a história de lutas contra a exploração mercantilista dos negros escravos: os quilombolas.

Assim, os quilombos, além de serem locais de refúgio na época da escravidão, também se tornaram a única forma de resistência dos ex-escravos após a Lei Áurea, pois não foi elaborada uma política pública pós-abolicionista, que concedesse um apoio socioeconômico aos negros.

O estilo de vida quilombola, não focado na produção excedentário-econômica, mas sim num estilo de vida mais comunitário (herança dos princípios usados na África e que fora reproduzido nas diásporas forçadas dos negros para o Brasil), vai de encontro à sociedade individualista brasileira inserida no modo de produção capitalista. Entretanto, mesmo no contexto desta sociedade capitalista brasileira, algumas políticas públicas focadas para os quilombolas têm sido construídas.

Dessa feita, para que possamos entender algumas políticas construídas no contexto brasileiro para os quilombolas, foi necessário retratar os significados da palavra quilombola por meio da historiografia deste conceito, seguindo o método historiográfico proposto por Walter Benjamim (1991), de forma a compreender o quanto o alcance desta palavra foi se modificando com o desenvolvimento da história brasileira. Além disso, por meio do método histórico demonstramos as discussões que envolveram a construção do artigo 68 do Ato das Disposições Constitucionais Transitórias (ADCT) da Constituição Federal Brasileira de 1988. Por último, analisamos as políticas públicas focadas para os quilombolas e suas limitações, destacando o Programa Brasil Quilombola.

\section{Evolução conceitual da palavra quilombola}

Etimologicamente, a palavra quilombo (kilombo - quimbundo) significa acampamento guerreiro na floresta. Essa expressão é originária dos povos bantus, que habitam na região de Angola. Para Simonsen (1970), inicialmente, era utilizada para designar um lugar de pouso ou também cemitério. A seguir, passou também a ser utilizada como locais de acampamento ou descanso de comerciantes de cera, escravos e também de outros produtos que eram do interesse dos colonizadores.

No Brasil, quilombo passou a ter outra conotação. Em 1740, surge a primeira conceituação brasileira de quilombo, tendo em vista uma resposta do rei de Portugal a uma consulta feita pelo Conselho Ultramarino. Na ocasião, foi conceituado como sendo "toda habitação de negros fugidos, que passem de cinco, em parte despovoada, ainda que não tenham ranchos levantados e nem se achem pilões nele" (ALMEIDA, 2002, p. 47), ou seja, transmitia a necessidade de 
isolamento geográfico para caracterizar quilombolas, além de uma ideia de resistência frente à opressão que os negros escravos sofriam. Em todo o Brasil, outras normas surgiram retratando este mesmo conceito dado ao Conselho Ultramarino, por exemplo, o artigo 12 da Lei 236/1847 da Assembleia Provincial do Maranhão e também a Lei 157/1848 do Rio Grande do Sul.

A nossa primeira Lei de Terras, que foi de 1850, manteve o conservadorismo fundiário do Brasil, pois estipulou que toda e qualquer aquisição de terras devolutas seria efetuada por meio da compra, o que já discriminou o escravo, porque o valor cobrado era inacessível ao recém-liberto, além também de os africanos e seus descendentes não poderem ter acesso à terra, pois não eram considerados brasileiros. Assim, já ficava demonstrada a vedação do escravo liberto em ter acesso à propriedade. Nesse contexto, podemos observar que a Lei Áurea (Lei 3353/1888) apenas extinguiu formalmente a escravidão no Brasil, não tendo sido elaborado um planejamento para aplicação de uma política compensatória aos negros, que permitisse o acesso desta população à terra.

Após esta época, a palavra quilombo só foi aparecer na Constituição Federal de 1988, por meio do artigo 68 do ADCT, onde está expresso: “Aos remanescentes das comunidades dos quilombos que estejam ocupando suas terras é reconhecida a propriedade definitiva, devendo o Estado emitir-lhes os títulos respectivos".

Entretanto, a utilização da expressão remanescentes das comunidades quilombolas pela Constituinte de 1988 fez renovar uma discussão teórica sobre o que poderia ser entendido por comunidades quilombolas. Assim, cabe levantar esta discussão através da historiografia sobre quilombolas no Brasil, pois, assim, podemos vislumbrar a ressemantização do termo quilombola.

Autores da época colonial como Gaspar van Barleu (1974) definiu quilombo como cativos fujões, que são nocivos à sociedade da época e que foram incapazes de se adaptar aos costumes civilizados. Além disso, justificou a utilização das forças repressoras para destruir os quilombos.

Já na época imperial da história brasileira podemos perceber uma certa ressemantização. $\mathrm{Na}$ legislação daquele período só eram necessários três escravos fugitivos, independentemente de serem formados em ranchos definitivos, para que houvesse a caracterização de quilombo. Os autores que retrataram a história do Império do Brasil deram ênfase à história do Quilombo de Palmares. Assim, Heinrich Handelmann (1982) defendeu a necessidade da destruição de Palmares, por constituir uma ameaça às intenções da Europa na América. Além disso, fez uma leitura sociológica do quilombo, considerando-o como uma microsociedade alternativa ao regime escravista.

Agostinho Perdigão M. Malheiro, em 1866, tratou o movimento quilombola sob um viés sociológico, dizendo que a fuga é inerente à escravidão, além de retratar as relações mercantis dos quilombolas com a sociedade escravista (MALHEIRO, 1976). 
Francisco Varnhagen, conhecido como Visconde de Porto Seguro, defendeu que destruir os quilombos e apreender escravos era um negócio vantajoso e também uma forma de civilizálos (VARNHAGEN, 1962).

Porém, na época da República, podemos vislumbrar um grande volume de ressemantizações no termo quilombola. Desta forma, Arruti (2008) divide estas ressemantizações em três principais: resistência cultural, resistência política e resistência negra, em que a resistência cultural deve-se ao fato do quilombola ser visto com uma forma de produção de uma cultura negra no Brasil. Percebe-se isto claramente em Nina Rodrigues (1905), que identificou o quilombo como um projeto restauracionista, no qual os quilombolas queriam restaurar a África no Brasil.

No mesmo sentido, Arthur Ramos (1934) descreveu o negro sob um viés étnico e racial, desprezando a percepção social como trabalhador escravizado. Já os quilombos, entendeu como reação da cultura negra em aceitar novos traços culturais.

Gilberto Freyre (1936) defendeu a superioridade racial e também cultural do colonizador. Descreveu a sociedade escravocrata como se houvesse uma harmonia entre os escravos e os escravizadores, além de ter qualificado Palmares como uma forma "parassocialista" de cultura e economia.

Ernesto Ennes (1938) destacou a necessidade de destruição de Palmares. Considerava o quilombo como uma volta às raízes africanas e defendia o castigo pedagógico ao negro que fugia. Neste sentido, Mário Martins de Freitas (1954) admitiu que o fenômeno quilombola era consequência de ausência de bons governos, vindo a defender a destruição de Palmares, que ele chamava de reino negro.

Já uma segunda perspectiva de ressemantização se deu com a ideia de quilombo como resistência política. Assim, Benjamin Péret (2002), em 1955, foi o primeiro a identificar a luta entre duas classes distintas, tendo proposto a destruição da escravidão através da luta dos escravizados, caso tivessem se juntado com as outras classes oprimidas. A busca da liberdade era o desejo em comum dos quilombolas. Na mesma seara, Clóvis Moura (1959) tratou o quilombo como uma forma fundamental de resistência numa sociedade dialética entre trabalhadores escravizados e escravizadores, o que, junto com Péret (2002), provocou uma mudança abrupta no sentido da palavra, pois não aceitaram mais quilombo como uma visão culturalista e sim como uma forma de resistência do trabalhador escravizado.

Diferentemente, Édison Carneiro (1964) retomou a ideia culturalista, pois retratou o quilombo como uma reafirmação da cultura africana, ou seja, uma resistência cultural.

Emília Viotti da Costa (1966), em plena Ditadura Militar no Brasil, ressaltou o caráter escravista na história do Brasil, mostrou a importância da escravidão para geração de riquezas e a violência contra o escravo como instrumento de mediação de uma sociedade cujo trabalhador escravizado era explorado pelos escravizadores. 
Luiz Luna (1968) lembrou que os escravos, diferentemente dos índios, não se submeteram ao cativeiro, por isso, retratou a luta do trabalhador escravizado mal tratado no cativeiro. Enquanto Décio Freitas (1973) confirmou a ideia de quilombo como uma expressão da luta de classes entre o trabalhador escravizado e o proprietário.

Robert Conrad (1978) defendeu que os quilombos aceleraram o fim do cativeiro do trabalhador escravizado, ou seja, o cativo como protagonista da própria abolição. Em outro sentido, Abdias do Nascimento (1980) expressa que o quilombo não expressa escravo fugido e sim uma reunião fraterna e livre, que vive em comunhão existencial. Defende uma revolução pacífica dos negros, de forma que recupere as tradições comunitárias africanas.

A terceira perspectiva de ressemantização, que se deu por influência do movimento negro, foi a que passou a entender quilombo como uma expressão da resistência negra, pois somou a perspectiva cultural com a perspectiva política.

Neste contexto, Kátia Mattoso (1982) trouxe à tona novamente as ideias defendidas por Nina Rodrigues, Arthur Ramos e Gilberto Freyre de que os quilombos são provenientes da resistência cultural que o africano teve à cultura da sociedade escravocrata brasileira. Da mesma forma, João José Reis (1986) retomou em parte a visão cultural de quilombo, pois deu destaque à resistência social e também à cultura africana.

Diferentemente, Mário Maestri (1986) identificou a resistência do escravo como uma luta de classes e o quilombo como meio para se alcançar a liberdade.

Assim, influenciados pela grande produção acadêmica de 1988, devido à comemoração dos cem anos de abolição no Brasil, tivemos autores como Carlos Magno Guimarães (1988), que defendeu que o quilombo não se define por meio do local e sim do elemento humano que o integra e também Alaôr Eduardo Scisinio (1988), para quem o quilombo foi uma forma de luta do trabalhador escravizado contra a escravidão.

Desta forma, os anos de 1980 e 1990 foram marcados pelos paradigmas que intercalaram a perspectiva culturalista e a influência do marxismo. Neste período, há a renovação da discussão uma vez que há uma desistência em buscar as "sobrevivências africanas".

Neste ínterim, o conceito de quilombola aparece no artigo 68 do ADCT da Constituição Federal de 1988. Além disso, a problemática quilombola adquiriu nova força no cenário nacional com a expedição do Decreto 4.887 de 20 de novembro de 2003, através do qual foi regulamentado, sob o pálio de critérios de autoatribuição, o procedimento de identificação, reconhecimento, delimitação, demarcação e titulação das terras ocupadas pelos remanescentes de quilombos de que trata o Art. 68 dos ADCT. Portanto, para continuarmos, é salutar a explicação do processo de criação do artigo 68 na época da Constituinte de 1988. 


\section{A construção do artigo 68 dos ADCT}

Inicialmente, é importante destacar que não houve registro de emendas populares para subsidiar a feitura do artigo 68 dos ADCT. Inclusive, Fiabani (2008) destaca que a ausência do movimento negro se deveu à questão fundiária não ter entrado nas discussões deste movimento na época da Constituinte de 1988.

Porém, Souza (2013) contesta esta tese, demonstrando que houve duas sugestões que impactaram a construção da política para o quilombola. Uma delas foi consequência do ciclo de debates do Centro de Estudos Afro-brasileiros, já a outra proposta foi da parlamentar Benedita da Silva, ambas em 1987.

A instalação da Assembleia Nacional Constituinte para a elaboração da Constituição Federal da República Federativa do Brasil de 1988 se deu em $1^{\circ}$ de fevereiro de 1987. E para que possamos, por meio do método histórico ${ }^{1}$, entender a construção do referido artigo, é preciso descrever em quais condições o mesmo fora elaborado. Para isso, faz-se necessário destacar que os trabalhos da Assembleia Nacional Constituinte foram divididos em oito comissões temáticas que, por sua vez, subdividiram cada comissão em três subcomissões. Desta feita, a construção da política relativa ao negro se deu na Comissão da Ordem Social, localizando-se mais especificamente na Subcomissão dos negros, populações indígenas, pessoas deficientes e minorias.

Dois meses após a instalação da Assembleia Nacional Constituinte já houve a discussão sobre o tema quilombola, com as propostas do Centro de Estudos Afro-brasileiros (Sugestão $\mathrm{n}^{\circ}$ 2.886, publicada no Diário Oficial de 09 de maio de 1987) e também de Benedita da Silva (Sugestão $n^{\circ}$ 9.015, publicada no Diário Oficial de 29 de maio de 1987).

No anteprojeto do relator da Subcomissão dos negros, populações indígenas, pessoas deficientes e minorias, o tema quilombola foi tratado no artigo $7^{\circ}$, com a redação: "O Estado garantirá o título de propriedade definitiva das terras ocupadas pelas comunidades negras remanescentes dos Quilombos". E esta redação seguiu sem alteração para análise da Comissão da Ordem Social. Ao chegar à comissão, teve um substitutivo do relator, modificando o seu texto para: "fica declarada a propriedade definitiva das terras ocupadas pelas comunidades negras remanescentes dos quilombos, devendo o Estado emitirlhes os títulos respectivos". Posteriormente, foi acrescentado ao final desta redação o seguinte: "Ficam tombadas essas terras bem como todos os documentos referentes à história dos quilombos no Brasil". Logo após, a Comissão de Sistematização, a quem coube sistematizar os dispositivos aprovados pelas Comissões Temáticas, elaborou o projeto de constituição e o artigo sobre quilombolas ficou no possível artigo 490 do esboço de Constituição Federal. Este foi o momento em que o projeto de artigo sobre quilombola foi mais atacado. Nesta ocasião, os contrários ao artigo 490 alegaram, por exemplo, que caso fosse aprovado este artigo, seria a criação de um apartheid no ordenamento brasileiro, ou seja, seria discriminatório (projeto apresentado pelo parlamentar Eliel Rodrigues do estado do Pará). Mas, após

1 No caso em tela, fizemos, por meio de pesquisas no site da Câmara dos Deputados, uma análise dos anais e diários da Assembleia Nacional da Constituinte de 1988 no que se refere à construção do artigo 68 do ADCT. 
essas discussões, a comissão, certamente também influenciada pelo centenário da abolição no Brasil, resolveu acatar o dispositivo relativo ao direito de propriedade dos quilombolas, porém o deslocando para o ADCT, e foi retirada a parte relacionada ao tombamento para o corpo constitucional. Surgindo, assim, o artigo 68 do ADCT com o seguinte texto: "Aos remanescentes das comunidades dos quilombos que estejam ocupando suas terras é reconhecida a propriedade definitiva, devendo o Estado emitir-lhes os títulos respectivos"

Logo, aparece a dúvida: por que houve o deslocamento do direito de propriedade quilombola para o ADCT? Isto devido ao ADCT ser o local para que constem normas que após serem implementadas tenham a sua eficácia exaurida (normas que já atingiram a produção dos seus efeitos) e também para normas que tiveram a função de serem utilizadas na transição entre a Constituição de 1967 e a de 1988.

Para Leite (2000), a razão desta localização no texto constitucional se deveu pelo fato de muitos parlamentares imaginaram que terras quilombolas eram casos raros, tais como o caso do Quilombo de Palmares.

No mesmo sentido, Fiabani (2008) ressalta que os parlamentares pensaram que apenas restavam poucas comunidades remanescentes de quilombos no Brasil, o que não necessitaria manter no corpo constitucional permanente logo após ser resolvido o problema fundiário dos quilombolas. Inclusive, retrata que a historiografia da época vislumbrava apenas o conceito de quilombo antigo, considerando quilombolas como comunidades de cativos fugidos. A noção de quilombos contemporâneos (comunidades negras em geral agrupadas num território) fora criada apenas em 1990.

\section{As políticas públicas focadas nos quilombolas}

As políticas públicas focadas nos quilombolas são norteadas por ações afirmativas específicas e somente a partir dos anos 2000 começaram a ser aplicadas no Brasil, por meio da Política Nacional de Promoção da Igualdade Racial (PNPIR), Programa Brasil Quilombola e também da criação da Secretaria Especial de Políticas e Promoção para a Igualdade Racial (SEPPIR).

Contudo, ainda existem muitos empecilhos para a efetivação de direitos quilombolas, tais como a burocracia institucional, a falta de recursos humanos especializados (por exemplo, antropólogos no Instituto Nacional de Colonização e Reforma Agrária (INCRA) e nos Centros de Referência de Assistência Social (CRAS)), localizados em comunidades tradicionais, acesso a informações pela população quilombola, dificuldade de infraestrutura, serviços públicos basilares de baixa qualidade, terras quilombolas em litígio de posse com latifundiários ou até mesmo com o interesse do governo, entre outros.

Mas, vamos iniciar esta parte falando das evoluções que a população quilombola teve a partir do início do século XXI. Uma das mais importantes foi a criação da Secretaria de Políticas de Promoção da Igualdade Racial (SEPPIR), em março de 2003, que teve status de ministério, 
sendo um órgão que presta assessoramento ao Presidente da República, com o fulcro de coordenar políticas para proteção dos direitos dos indivíduos e grupos raciais e étnicos, principalmente a população negra, que fora vítima de discriminação e também de diversas formas de intolerância. Esta secretaria também articulava e promovia, junto com outros ministérios, iniciativas com o objetivo de mitigar a desigualdade racial.

Vale destacar que em outubro de 2015, com as reformas ministeriais, houve a absorção da SEPPIR a outras secretarias - das Mulheres e dos Direitos Humanos - formando o Ministério das Mulheres, Igualdade Racial e Direitos Humanos, o que veio a enfraquecer a luta da categoria quilombola.

Outro marco histórico na construção de políticas públicas para os quilombolas deu-se em novembro de 2003, por meio do Decreto Federal 4886/2003, a Política Nacional de Promoção da Igualdade Racial (PNPIR), cujo objetivo central é a redução das desigualdades étnicas no contexto brasileiro, mormente a população negra, por meio de programas e projetos a serem executados a longo, médio e curto prazo. Estão previstos nesta política nacional os seguintes princípios de gestão: a) transversalidade, em que há a participação de vários órgãos na execução e gestão das ações para combater as desigualdades raciais; b) gestão descentralizada, em que se busca articular os entes federativos; c) gestão democrática, por meio do diálogo com a sociedade civil participante da luta quilombola.

Em março de 2004, foi criado o Programa Brasil Quilombola (PBQ), já em 2007, o Decreto Federal 6.261/2007, que trata da agenda social no âmbito do PBQ. Este trata de ações de um comitê gestor envolvendo 11 ministérios sob a coordenação da SEPPIR. Este Programa tem 04 eixos temáticos: a) acesso à terra; b) infraestrutura e qualidade de vida; c) desenvolvimento local e inclusão produtiva; d) direitos e cidadania.

Em 2007, foi criada mais uma política para a concretização dos direitos quilombolas, através do Decreto Federal 6.040. A Política Nacional de Desenvolvimento Sustentável dos Povos e Comunidades Tradicionais tem foco na promoção do desenvolvimento sustentável com ênfase na garantia de direitos territoriais, sociais, ambientais, culturais e econômico, buscando a valorização da identidade dos povos.

Também em 2007 houve o lançamento do Programa de Aceleração do Crescimento Quilombola (PAC Quilombola) com a finalidade de melhorar o acesso à educação, saúde, infraestrutura, por meio de edificação de estradas, abastecimento de água e também a regularização fundiária.

Há também a Portaria 98/2007 da Fundação Cultural Palmares, que regulamenta o procedimento de certificação das comunidades quilombolas, além da Instrução Normativa 57/2009 do INCRA que, por sua vez, prevê o procedimento para identificação, delimitação, demarcação, desintrusão e titulação das terras quilombolas.

Outra legislação que repercute para os quilombolas é a Lei 12.288/2010, que se refere ao Estatuto da Igualdade Racial. 


\section{Dialogando com o Programa Brasil Quilombola}

Cabe iniciar este tópico ressaltando que as ações em relação ao tema quilombola só adentraram para o plano plurianual ${ }^{2}$ em 2004-2007 e isto se deu devido à construção do PBQ, em 2004, que tem por finalidade a efetividade de políticas públicas para as comunidades quilombolas no âmbito do território brasileiro.

No plano plurianual de 2012-2015, a questão quilombola também se fez presente através da rubrica "enfrentamento ao racismo e promoção da igualdade racial". E esta inclusão no Plano Plurianual é de suma importância por permitir a previsão de parcela orçamentária para ações, monitoramento e avaliações de políticas para as comunidades quilombolas.

Vale ressaltar que a efetivação do PBQ também dialoga com o Programa Brasil sem Misérias à medida que, conforme Guia de Políticas Públicas para Comunidades Quilombolas, 2013, do SEPPIR, 74,73\% das famílias quilombolas estão abaixo da linha da extrema pobreza.

É interessante ser feito um estudo sobre o nível de execução do Programa Brasil Quilombola sob o olhar dos 4 eixos temáticos deste programa. O primeiro eixo, acesso à terra, é aquele que se preocupa com a execução e também monitoramento dos procedimentos relacionados à regularização das terras onde estão imersas as comunidades quilombolas, ou seja, acompanhamento do processo, desde a certificação como comunidade quilombola, até a devida titulação. Inclusive, a concretização do direito fundamental da comunidade quilombola à terra coletiva é extremamente burocrática. Ocorre uma contradição para comunidades que têm, em geral, um baixo grau educacional e ao mesmo tempo têm dificuldades no acesso ao judiciário por meio da Defensoria Pública, haja vista que tem um déficit de defensores públicos. Além disso, a regularização fundiária envolve diálogo com vários setores públicos, pois o desenvolvimento da política agrária no Brasil está a cargo do Ministério de Desenvolvimento Agrário, através do INCRA, havendo também o acompanhamento da SEPPIR e da Fundação Cultural Palmares (FCP).

Há uma baixa quantidade de certificações concedidas para as comunidades quilombolas se comparado com as comunidades existentes. De acordo com o Guia de Políticas Públicas para Comunidades Quilombolas da SEPPIR (2013), foram certificadas pela FCP, até 2013, apenas 2040 comunidades quilombolas. Já quando se fala em titulação, o número ainda é mais modesto, pois, até 2013, apenas 207 comunidades quilombolas tinham sido tituladas pelo INCRA.

Isso demonstra que apesar de a titulação dos territórios quilombolas ser a base para a existência dos outros três eixos do PBQ - já que ele consolida o passo fundamental da comunidade ser reconhecida juridicamente como tal e ser concedido o seu direito de acesso à terra para que haja a continuidade da sua cultura e identidade - ainda é o eixo onde há a efetivação mais baixa das políticas públicas para os quilombolas.

3 O Plano Plurianual é um plano de médio prazo (previsto no artigo 165 da Constituição Federal de 1988) que estabelece as diretrizes, objetivos e metas a serem seguidos pelo Governo Federal, Estadual ou Municipal ao longo de um período de quatro anos. 
Já no segundo eixo, infraestrutura e qualidade de vida, busca-se materializar obras de infraestrutura para as comunidades quilombolas, tais como eletricidade, saneamento, habitação e comunicação. Além disso, neste eixo foca-se também a efetivação de políticas sociais, como educação, saúde e assistência social.

No setor de eletricidade, podemos destacar o Programa Luz para Todos (PLPT), que é um dos programas afeitos aos quilombolas, foi criado pelo Governo Federal visando levar energia elétrica para a população do meio rural, seja ela com ou sem recursos financeiros, de forma gratuita.

O PLPT foi lançado em novembro de 2003 com o desafio de acabar com a exclusão elétrica no país. A meta era levar energia elétrica para mais de 10 milhões de pessoas do meio rural até o ano de 2008, tendo sido atingida em maio de 2009. Em 2012, segundo dados da SEPPIR (Relatórios de gestão da SEPPIR 2012 e 2013), 26.345 domicílios em comunidades quilombolas foram alcançados pelo PLPT.

Já em relação ao saneamento nas comunidades quilombolas, percebe-se que os recursos investidos em comunidades quilombolas ainda são baixos, se comparados com a quantidade de comunidades já certificadas e em processo de certificação.

O órgão federal competente, no que se refere ao saneamento de comunidades quilombolas, é a Fundação Nacional de Saúde (FUNASA) e segundo a SEPPIR (2013), no PPA 2012-2015 há o objetivo de implantar obras de saneamento em 375 comunidades quilombolas, o que é uma pretensão muito abaixo do esperado para um Plano Plurianual que planeja os recursos para 04 anos.

Junto a isto, há um programa, o "Água para todos", que foca na construção de cisternas para recolhimento de água de chuvas no semiárido. Este programa conta com a gestão e execução da FUNASA, MDS e Ministério da Integração Nacional (MIN).

A política de habitação para os quilombolas busca ser concretizada por meio de um programa que é bastante amplo - não sendo específico para as comunidades quilombolas que é o Programa Nacional de Habitação Rural, que integra o Programa Minha Casa Minha Vida, que serve para auxiliar comunidades indígenas, quilombolas e de trabalhadores rurais, tais como agricultores e pescadores. Porém, devido à burocracia, para se receber esses recursos específicos, esse programa vem alcançando poucas famílias quilombolas. Segundo dados da Caixa Econômica Federal, até 2014, tinham sido beneficiadas apenas 1700 famílias quilombolas.

Além disso, o número de unidades habitacionais ainda é muito baixo em comunidades quilombolas, o que demonstra a necessidade de ser construída uma política habitacional específica para os quilombolas, que inclusive respeite a sua cultura e a sua identidade (SEPPIR, 2013).

Outra discussão importante relaciona-se à questão da ampliação das comunicações para os quilombolas, por exemplo, através da inclusão digital. Assim, cabem algumas considerações. Entendemos que a inclusão digital também pode ser um propiciador da melhoria das condições 
de vida dos indivíduos, possibilitando uma redução das desigualdades sociais. Porém, para que haja esta inclusão, precisa necessariamente se ter uma melhoria educacional dos quilombolas, que permita que os indivíduos tenham capacidade para serem cidadãos ativos na sociedade informacional. ${ }^{4}$

Há autores, como Assumpção e Mori (2006), que defendem que a inclusão digital é propiciadora da inclusão social, o que melhoraria as condições de comunidades antes isoladas. Contudo, na verdade, a inclusão digital ainda não promoveu esta inclusão social, e sim uma acentuação das desigualdades sociais, ou seja, está aumentando o abismo entre ricos e pobres, pois apenas o acesso às Tecnologias da Informação e Comunicação (TIC’s) não foi suficiente para melhorar as condições de vida das classes mais pobres.

Temos que lembrar que a falta de acesso às informações disponibilizadas pelas TICs aumenta o fosso ( $g a p$ ) entre os cidadãos que tiveram acesso à informação e aqueles que foram excluídos deste acesso. Desta forma, a exclusão digital afeta diretamente a inclusão social, ou seja, falar em inclusão digital é falar em cidadania, em igualdade entre os indivíduos.

Neste sentido, há a necessidade do desenvolvimento da capacidade cognitiva para que os indivíduos possam processar as informações de forma que sejam estimuladores da melhoria de vida dos indivíduos, ou seja, sejam cidadãos ativos e críticos na sociedade em redes.

Como lembra Pinheiro (2007), a inclusão digital não deve ser entendida apenas como acesso às TICs, à rede, a jogos. Além disso, o indivíduo não deve se restringir a somente localizar a informação, deve sim ser capaz de entender a informação, avaliá-la e usá-la, proporcionando o autoaprendizado.

Já Silva Filho (2003) ressalta que a inclusão digital envolve três pilares, que são as TICs, a renda e a educação. Isto porque mesmo que haja o acesso à renda, faz-se necessário o pilar da educação, pois apenas o acesso à renda e às TICs não será propiciador de uma boa funcionalidade da informação.

Portanto, apenas conceder acesso a baixo custo de computadores às pessoas não é inclusão digital, é necessário também ensiná-los a utilizar estas ferramentas digitais de forma eficaz, maximizando as informações acessadas e sendo um sujeito crítico ativo destas informações colhidas nas TICs.

O terceiro eixo do PBQ é a inclusão produtiva e desenvolvimento local. Neste, objetivase o estímulo ao desenvolvimento produtivo local e geração da independência econômica das comunidades quilombolas, respeitando-se a sua cultura e recursos naturais envolvidos nos seus territórios.

Um programa que se relaciona a este eixo é o Programa Nacional de Fortalecimento da Agricultura Familiar (PRONAF), servindo para financiar projetos individuais ou coletivos,

\footnotetext{
4 Essa melhoria educacional que defendemos não é a defesa da teoria do capital humano, pois entendemos que não é por meio da educação que haverá a capacitação para o trabalho, e sim que a melhoria educacional provocará uma maior socialização de informações importantes nessa nova perspectiva de sociedade - a cibersociedade.
} 
que possibilitem a geração de renda aos agricultores familiares e assentados da reforma agrária. O programa possui as mais baixas taxas de juros dos financiamentos rurais. Será considerado crédito coletivo quando formalizado por grupo de produtores para finalidades coletivas.

O agricultor terá que transcorrer alguns passos para ter acesso a este programa, em que o primeiro passo é um diálogo com a família em relação à identificação da carência do crédito, se será para custear a safra ou atividade agroindustrial ou para que haja investimentos para aquisição de máquinas, equipamentos ou infraestrutura de produção e serviços agropecuários ou não agropecuários.

Posteriormente, após a decisão do que financiar, a família deve procurar o sindicato rural ou a empresa de Assistência Técnica e Extensão Rural (ATER), como a Emater, para obtenção da Declaração de Aptidão ao PRONAF (DAP), que será emitida segundo a renda anual e as atividades exploradas, direcionando o agricultor para as linhas específicas de crédito a que tem direito. Para os beneficiários da reforma agrária e do crédito fundiário, o agricultor deve procurar o INCRA ou a Unidade Técnica Estadual (UTE).

Cabe salientar que o agricultor deverá estar com o Cadastro de Pessoa Física (CPF) regularizado e livre de dívidas. As condições de acesso ao Crédito PRONAF, formas de pagamento e taxas de juros correspondentes a cada linha são definidas, anualmente, a cada Plano Safra da Agricultura Familiar, divulgado entre os meses de junho e julho. Porém, há alguns empecilhos para a concretização do PRONAF em comunidades quilombolas. Inicialmente, cabe lembrar a dificuldade de acesso às informações relacionadas a este programa. Seria interessante haver a participação governamental e também da sociedade civil no sentido de estimular a divulgação e capacitar esta população (onde existe uma alta de taxa de analfabetismo) para entender o programa. Outro grande problema relaciona-se à documentação, pois muitos destes quilombolas não tiveram acesso aos seus documentos básicos, tais como identidade (RG) e CPF.

Assim, precisa haver a desconstrução destes obstáculos e a construção de pontes que interliguem o acesso ao PRONAF. Desta feita, precisa o INCRA ir até essas comunidades quilombolas para facilitar a emissão da Declaração de Aptidão ao PRONAF (DAP).

O quarto eixo do PBQ é direitos e cidadania, em que se procura estimular a participação dos variados órgãos públicos e também da sociedade civil organizada de forma a se ter a presença e voz ativa dos representantes das comunidades quilombolas nos conselhos locais, regionais ou nacionais de políticas públicas focadas nas comunidades quilombolas, fomentando a construção de políticas públicas para os quilombolas de forma participativa, principalmente, com a participação ativa dos quilombolas. É no contexto deste eixo, por meio da efetivação das políticas sociais de educação, saúde e assistência social, que haveria o fortalecimento dos direitos e da cidadania quilombola. 


\section{Considerações Finais}

Trabalhar com os quilombolas é entender a diversidade étnica da população brasileira, é promover um diálogo entre o passado de luta com uma sociedade escravocrata, mas também é saber que ainda há uma luta fervilhando contra uma sociedade individualista gestada no seio do capitalismo, onde o modo de vida e cultura quilombola conflita com os interesses hegemônicos (tais como, os interesses de latifundiários), cuja burocracia na titulação ratifica mais ainda a história de opressão aos negros.

Entendemos que os direitos não serão completamente efetivados para os quilombolas se eles próprios não tiverem organizados e forem capazes de entender estes direitos, pois a conquista e efetivação dos direitos se dão por meio das lutas sociais, e estas dependem da capacidade da comunidade ter voz ativa perante uma sociedade que é preconceituosa e discriminatória, muito marcada pela "cultura branca".

No que se refere às políticas públicas focadas na população quilombola, destacamos que programas como o $\mathrm{PBQ}$, que tem por objetivo concretizar políticas públicas específicas para estas comunidades, não vem alcançando as peculiaridades de cada comunidade.

Neste sentido, urge a concretização do direito fundamental à terra (política mais ampla e basilar para todas as comunidades quilombolas), pois as relações que os quilombolas têm com as terras de habitação e/ou cultivo são cruciais para a construção da própria cidadania quilombola. Assim, defendemos que, a partir da introdução do artigo 68 do ADCT à Constituição Federal de 1988, foi assegurado o direito à terra para os quilombolas. Portanto, a regularização fundiária definitiva é o caminho para construção da cidadania desse grupo, pois permitirá que haja uma segurança jurídica para os quilombolas, caso seja pensada concomitantemente com políticas públicas específicas para esta população.

\section{Referências}

ALMEIDA, Alfredo Wagner Berno de. Os quilombos e as novas etnias. In: O'DWYER, Eliane Cantarino (Org.). Quilombos identidade étnica e territorialidade. Rio de Janeiro: FGV; ABA, 2002.

ARRUTI, José Maurício Andion. Quilombos. In: Raça: perspectivas antropológicas. ABA, Ed. Unicamp, EDUFBA, 2008.

ASSUMPÇÃO, Rodrigo; MORI, Cristina. Inclusão digital: discursos, práticas e um longo caminho a percorrer. 2006. Disponível em: <http://www.inclusaodigital.gov.br/noticia/inclusao-digitaldiscursos-praticas-e-um-longo-caminho-a-percorrer>. Acesso em: 15 jul. 2015.

BARLEU, Gaspar. História dos feitos recentemente praticados durante oitos anos no Brasil. São Paulo: Edusp, 1974.

BENJAMIN, Walter; TIEDEMANN, Rolf; SCHWEPPENHAUSER, Hermann. Gesammelte Schriften. Frankfurt am Main: Suhrkamp, 1991.

CARNEIRO, Édison. Ladinos e crioulos: estudos sobre o negro no Brasil. Rio de Janeiro: Civilização Brasileira, 1964. 
CONRAD, Robert. Os últimos anos da escravatura no Brasil: 1850-1888. 2 ed. Rio de Janeiro: Civilização Brasileira, 1978.

COSTA, Emília Viotti da. Da senzala à colônia. São Paulo: Difel, 1966.

ENNES, Ernesto. As guerras nos Palmares: subsídios para a sua história. São Paulo: CEN, 1938.

FIABINI, Adelmir. Os novos quilombos: luta pela terra e afirmação étnica no Brasil 1988-2008. 275 f. Tese (Doutorado em História) - Unisinos, São Leopoldo, 2008.

FREITAS, Décio. Palmares: a guerra dos escravos. Porto Alegre: Movimento, 1973.

FREITAS, Mário Martins de. Reino negro de Palmares. Rio de Janeiro: Americana, 1954.

FREYRE, Gilberto. Sobrados e mucambos: decadência do patriarcado rural no Brasil. São Paulo: Companhia Editora Nacional, 1936.

GUIMARÃES, Carlos Magno. Uma negação da ordem escravista: quilombos em Minas Gerais no século XVIII. São Paulo: Ícone, 1988.

HANDELMANN, Heinrich. História do Brasil. São Paulo: Edusp, 1982.

LEITE, Ilka Boaventura. Os quilombos do Brasil: questões conceituais e normativas. Etnográfica, v. 4, 2000. n. 2 , Centro em Rede de Investigação em Antropologia, Lisboa, p. 333-354

LUNA, Luiz. O negro na luta contra a escravidão. Rio de Janeiro: Leitura S. A, 1968.

MAESTRI, Mário. Breve história da escravidão. Porto Alegre: Mercado Aberto, 1986.

MALHEIRO, Perdigão. A escravidão no Brasil: ensaio histórico, jurídico, social. 3 ed. Petrópolis: Vozes, 1976.

MATTOSO, Kátia M. de Queirós. Ser escravo no Brasil. São Paulo: Brasiliense, 1982.

MOURA, Clóvis. Rebeliões da senzala: quilombos, insurreições, guerrilhas São Paulo: Zumbi, 1959.

NASCIMENTO, Abdias. Quilombismo. Petrópolis: Editora Vozes, 1980.

PÉRET, Benjamin. O quilombo dos Palmares? Porto Alegre: Editora da UFRGS, 2002.

PINHEIRO, Marta Macedo Kerr. Observatório da inclusão digital: descrição e avaliação dos indicadores adotados nos programas governamentais de infoinclusão. Encontro Nacional de Pesquisa em Ciência da Informação. In: VIII ENANCIB. Anais... Salvador: 2007.

RAMOS, Arthur. O negro brasileiro. Rio de Janeiro: Civilização Brasileira, 1934.

REIS, João José. Rebelião escrava no Brasil: a história do levante dos malês em 1835. São Paulo: Brasiliense, 1986. RODRIGUES, Nina. Os africanos no Brasil. 3. ed. São Paulo: CEN, 1905.

SCISINIO, Alaôr Eduardo. Escravidão e a saga de Manuel Congo. Rio de Janeiro: Achiamé, 1988.

SECRETARIA DE POLÍTICAS DE PROMOÇÃO DA IGUALDADE RACIAL - SEPPIR. Guia de políticas públicas para comunidades quilombolas 2013. Disponível em: <http://www.seppir.gov.br/arquivos-pdf/guia-pbq> Acesso em: 09 ago. 2015.

SILVA FILHO, Antonio Mendes da. Os três pilares da inclusão digital. Revista Espaço Acadêmico, v. 3, n. 24 , Maio 2003. SIMONSEN, Mário Henrique. Legitimidade da Monarquia no Brasil. Brasília: Editora Universidade de Brasília, 1970. SOUZA, Rodrigo Gonçalves de. Luta por reconhecimento e processo legislativo: a participação das comunidades remanescentes de quilombos na formação do art. 68 do ADCT. 2013. 265 f. Dissertação (Mestrado em Direito)— Universidade de Brasília, Brasília, 2013.

VARNHAGEN, Francisco Adolfo de. História geral do Brasil: antes de sua separação e independência de Portugal. 7. ed. São Paulo: Melhoramentos, 1962. 